Session 1615

\title{
Effective Teaching and Learning of Composite Materials for Undergraduate Civil Engineering Students
}

\author{
Julio F.Davalos, Pizhong Qiao \\ West Virginia University / University of Akron-OH
}

\begin{abstract}
Motivated by two pressing concerns in engineering education, a general need for creating efficient learning environments and a specific need to educate civil engineering students in advanced composite materials (ACM), this paper is concerned with a NSF-supported effort for developing teaching guides for ACM in civil engineering curricula. The approach is based on "active learning," which consists of integrating innovative laboratory techniques with computer modeling and visualization tools to create an interactive and a collaborative team-oriented environment for students to dynamically participate in their own learning. An active learning approach is used to develop the instructional materials for ACM. The goal of the "active learning" curriculum is to create an effective learning environment where students enjoy "hands-on" experiences through laboratory experiments and computer simulations and illustrations. The general objectives of this study are: (a) to develop a framework on active learning approach, (b) to apply this framework to design teaching modules on fundamentals and applications of ACM; and (c) to translate the teaching guides into multimedia applications for use at other universities, using the Internet as a delivery medium. The developed teaching guides have been successfully implemented at West Virginia University and at the University of Akron, $\mathrm{OH}$.
\end{abstract}

\section{Introduction}

The teaching styles and modalities used by most engineering faculty are usually based on observation and common sense, and perhaps even familiarity with the "scientific method," which may be a good intuitive model for teaching and learning. Upon close examination of the literature on effective teaching, one quickly recognizes that while "good teaching can be described and evaluated, the art and science of teaching remain in a primitive state of development;" ${ }^{1}$ however, the combination of selected fundamental principles with existing or emerging teaching technologies can be beneficial for improving the quality of learning and teaching in the classroom. In addition to the obvious benefits for students and the satisfaction Proceedings of the 2003 American Society for Engineering Education Annual Conference \& Exposition Copyright (c) 2003, American Society for Engineering Education 
derived by the instructor, the experience and knowledge gained through efforts directed to improving teaching can be effectively combined with research interests and evolve into integrated research-educational projects

This paper describes an "active learning approach" for teaching and learning of Advanced Composite Materials (ACM) in Civil Engineering. The NSF Combined Research Curriculum Development (CRCD) program has provided financial support for this study. The paper is organized in two complementary sections: (1) active learning of ACM through laboratory experiments and computer modeling, and (2) innovative teaching guides for ACM in Civil Engineering. A dissemination program of the developed teaching guides using the Internet as a delivery medium is under development and is briefly mentioned in this article.

\section{Active Learning of Advanced Composite Materials}

Motivation: In general, most students in sciences and engineering have difficulty in mastering fundamental concepts and basic principles; one possible reason for this deficiency in studentlearning may be that the classical lecture-mode of teaching by itself is not sufficient for students to grasp basic concepts. This learning difficulty, when coupled with the inherent complexity of composite materials, may require the implementation of innovative approaches for teaching ACM to civil engineering students. When learning advanced materials, it is important for students to develop physical visualization and conceptual understanding of the material structure at several levels (microstructure, constituents, and lay-up assemblies) and their properties and behaviors (orientation-dependent properties due to anisotropy and their influence on responses). In addition, students must acquire a sound command of analytical methods (e.g., matrix operations and analytical mechanics) and an appreciation of the design flexibility offered by composite materials (tailor-ability). These concepts are not usually part of civil engineering curricula and yet form the bases for design and applications of structural composites in civil infrastructure.

Objective: The motivation for this study combines two pressing concerns in engineering education: a general need for creating efficient learning environments and a specific need to educate civil engineering students in advanced composite materials. Although substantial research in ACM has been accomplished in the U.S. and abroad, the advances in this important area have not yet been fully integrated into undergraduate and graduate civil engineering curricula, due primarily to the lack of teaching guides for faculty to use and follow. A world survey of composites in civil engineering programs was recently completed by the Editorial Board of the ASCE Journal of Composites for Construction.$^{2}$ In the present study, our objective is to develop teaching guides for ACM by providing an effective learning environment for senior undergraduate and beginning graduate students to grasp fundamental concepts while enjoying "hands-on" experiences through laboratory experiments and computer simulations.

Overall Approach: In the context of the classroom, "active learning" may be defined as anything that "involves students in doing things and thinking about the things they are doing." 3 When active learning activities include the use of technology (e.g., multimedia applications), it is advisable to keep in mind that technology "tools" must be used in the framework of knowledge

Proceedings of the 2003 American Society for Engineering Education Annual Conference \& Exposition Copyright (c) 2003, American Society for Engineering Education 
of learning and teaching for a particular application. ${ }^{4}$ Our approach consists of integrating portable laboratory experiments and computer modeling into classical lecture topics of mechanics of composites. In contrast to a traditional teaching environment where the student retention of information drops to about $20 \%$ after 30 minutes of lecture ${ }^{5}$ (see Fig. 1), our goal and challenge is to promote an interactive, collaborative, and team-oriented environment for students to participate dynamically in their own learning; the laboratory sessions provide an opportunity for students to inquire, explore, collaborate, learn how to learn (life-long learning), and have fun while learning.

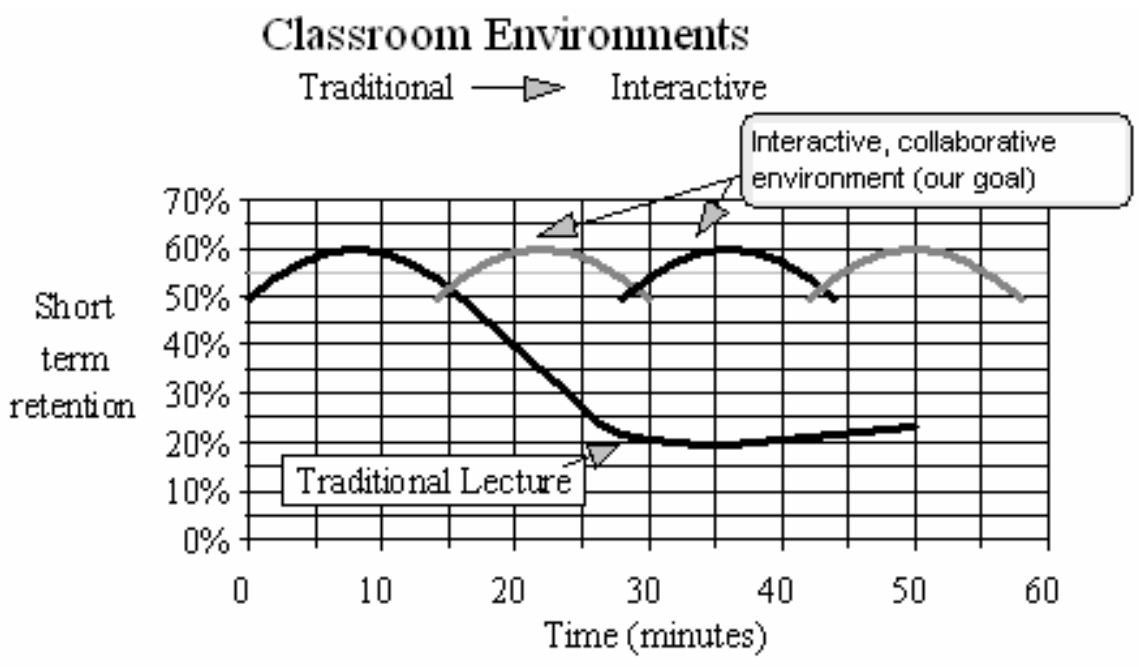

Figure 1 Short-term retention in two types of classroom environments ${ }^{5}$.

Guiding Principles: Following previous studies by Holzer et al. ${ }^{6,7}$ and Davalos et al. ${ }^{8}$, the primary guiding principle used in the design of the "active learning" activities is "constructivism," supplemented by "experiential learning" and "continuous learning." The principle of constructivism ${ }^{9}$ can be expressed as: "knowledge must be constructed by the learner; it can not be supplied by the teacher," ${ }^{6}$ as notably illustrated by the Farsi proverb: $A$ well must produce its own water. The implications are: "We are all responsible for our own learning, and the teacher is responsible for creating an effective learning environment. ${ }^{7}$ This is the foundation for experiential learning, ${ }^{10}$ where learning is not simply an additive process but requires actively engaging the learner. ${ }^{1}$

The laboratory sessions provide an excellent forum for experiential learning, where students in teams of three or four collaborate on either physical experiments or computer modeling. Based on Kolb's experiential learning model, ${ }^{10}$ where the two modes of learning are grasping and transforming experience (see Fig. 2), each laboratory topic is designed to include two or more of a four-stage learning cycle. For example, students participate in the fabrication of a composite laminate by hand lay-up (Figure 3) in order to gain hands-on experience on constituent materials and manufacturing, and then, they conduct experimental coupon testing (Fig. 4) to characterize the anisotropic nature of unidirectional composites, and it involves (1) experiment: students applied tensile loads to longitudinal (along the fiber direction) and transverse (normal to the fiber

Proceedings of the 2003 American Society for Engineering Education Annual Conference \& Exposition Copyright (c) 2003, American Society for Engineering Education 
direction) coupon samples and observe the deformation and failure (ultimate failure loads and modes), (2) analysis: from the observed behaviors, they infer that the longitudinal stiffness and strength are much higher than the ones in the transverse direction, (3) hypothesis: they propose a conceptual model regarding the anisotropic properties of composites (e.g., the Young's modulus $\left(E_{1}\right)$ in the fiber direction is over three times larger than the one $\left(E_{2}\right)$ in the transverse direction); and (4) testing: subsequently, they verify the experimental results and test their hypothesis by conducting computer modeling of various laminates, for which they obtain the properties of composites for different lay-ups and fiber volume fractions and observe the anisotropy, coupling effects, and design flexibility of composites. The computer software used for design of composites simplifies the computational process (e.g., micro- and macro-mechanics and failure criteria) for analyzing composites and provides an opportunity for students to explore the behaviors of composites, including those tested in the laboratory. Moreover, the use of the computer program reinforces the learning of fundamental concepts, such as mechanics of constituent layers and laminated assemblies.

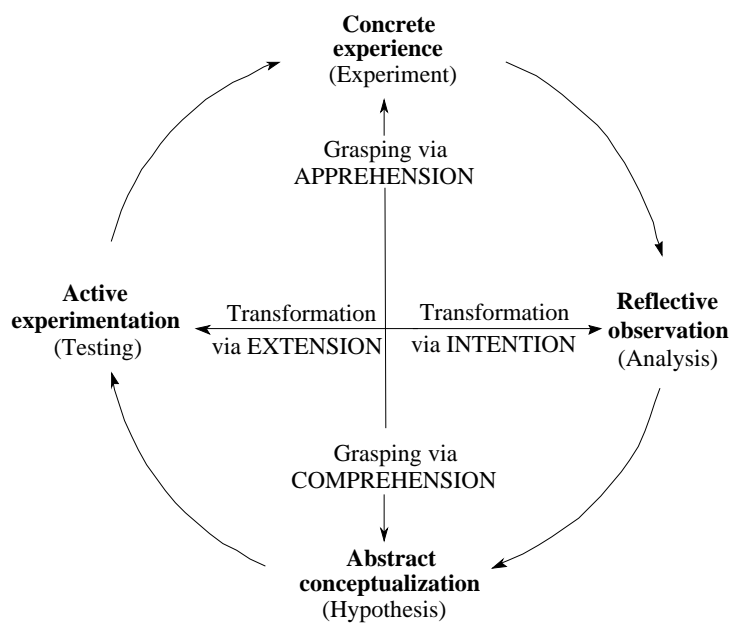

Figure 2 Model for experiential learning and associated knowledge forms ${ }^{10}$.

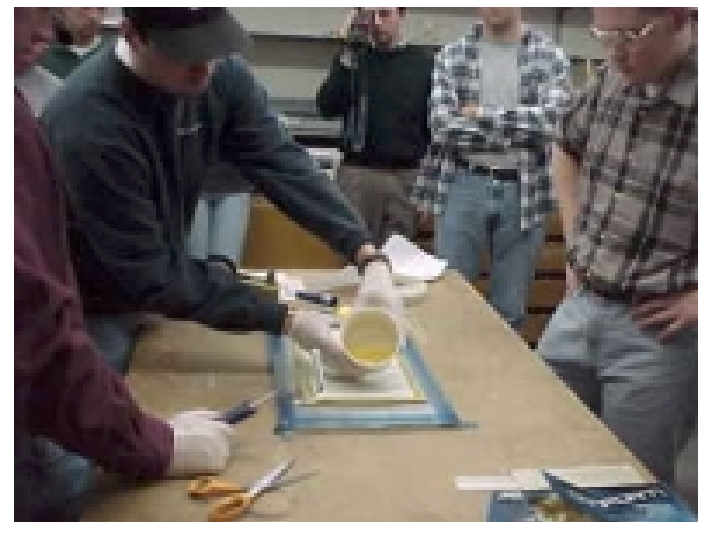

Figure 3 Hands-on manufacturing of a composite plate.

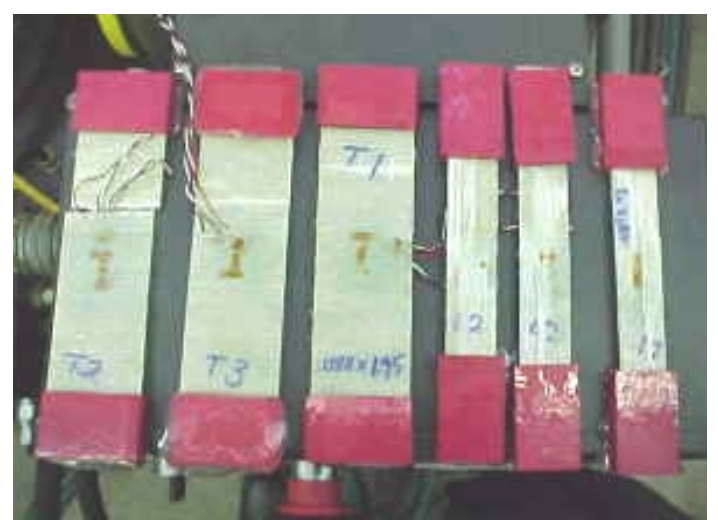

Figure 4 Coupon tensile tests of unidirectional composites in transverse and longitudinal directions.

Proceedings of the 2003 American Society for Engineering Education Annual Conference \& Exposition Copyright (c) 2003, American Society for Engineering Education 
After each laboratory session, students submit a report following prescribed guidelines. In addition, selected student teams make presentations on specific assigned topics or deliver 15minute mini-lectures during the class period on assigned concepts. These activities are designed to foster our "continuous learning" principle: "learning ... is what virtually all adults will do for a living by the beginning of the 21st century." 11 The implications are: Learning will be a life-long journey; your well-being will depend on your learning skills. ${ }^{7}$

\section{Innovative Teaching Guides for ACM in Civil Engineering}

Based on the "active learning" approach described above, we have developed teaching modules for Advanced Composite Materials (ACM) in Civil Engineering.

National Significance: The use of advanced composite materials in civilian applications has been motivated primarily by the need to improve and rehabilitate our nation's infrastructure. ACM are lightweight, noncorrosive, nonmagnetic, and nonconductive, and their stiffness and strength properties can be easily tailored to meet structural demands. Current applications of ACM structural components include antenna enclosures, chemical and waste-treatment plants, buildings, and bridges. Two of the most promising applications of composites in infrastructure are: (1) the rehabilitation of structures, such as wrapping of concrete bridge piers to sustain earthquake loads; for example, CaLTRAN's seismic retrofit program of two billion dollars is geared substantially towards the use of ACM, and (2) replacement and new construction of bridge decks using advanced composite panel systems; several new bridge decking systems have been built with composite materials. The favorable properties of composite materials make them suitable for reinforcement of conventional materials such as wood, concrete, and steel. The current applications of composites in civil structures are significant, and the use of ACM in the future is expected to increase dramatically. A state-of-the-art survey of composites for construction applications in civil engineering was published in May of 2002 by a selected group of members of the Editorial Board of the ASCE Journal of Composites for Construction. ${ }^{12}$

Need: Significant research results on ACM have been reported by investigators in the U.S. and abroad. However, the advances in ACM have not been fully translated into instructional guides for faculty to develop and teach undergraduate/graduate courses on design of ACM structures. At a hearing on "Uses of Advanced Materials in Civil Infrastructure," before the U.S. Senate Subcommittee on Science, Technology, and Space (May 27, 1993), Davalos and Barbero ${ }^{13}$ identified the lack of awareness of composite materials by the civil engineering community as a major barrier to the implementation and commercialization of composites in construction. A need exists to educate civil engineers in the design of advanced composite materials. Currently, most administrators and engineers in private practice and federal and state agencies lack formal education in composite materials and yet bear the responsibility for making material choices. This problem is compounded by the lack of design guidelines that can be used as references by civil engineers. As recognized by researchers in this field, "the civil engineering community must be educated in the design and application of these new construction materials." 14

Teaching Guides: The appropriate education of future engineers in this area can have a notable

Proceedings of the 2003 American Society for Engineering Education Annual Conference \& Exposition Copyright (c) 2003, American Society for Engineering Education 
impact in improving the nation's infrastructure, and based on our research expertise in structural applications of composites and hybrid materials, we have developed primarily undergraduate courses in design analysis of ACM and hybrid materials for civil engineering students. The instructional program (Fig. 5) consists of introduction of fundamental knowledge on composites, composites mechanics and design, and their applications (e.g., reinforcement of wood and concrete).

An "active learning" approach is adopted by combining classical methods of analysis with laboratory experiments and computer modeling. Based on the authors' research experience with fiber-reinforced structural shapes, several physical experiments (see Laboratory Sessions in Figure 5) were developed, such as an ACM beam under bending (Figure 6), ${ }^{15,16}$ lateral buckling of an ACM beam (Figure 7), ${ }^{17,18}$ lateral and local buckling of an ACM column (Figure 8). ${ }^{19,20,21}$ Also field trips were organized to visit composite manufacturing plants (e.g., visiting the manufacturing facilities of Creative Pultrusions Inc., Figure 9). A user-friendly software with web-browser-like graphics interface, titled Computer Aided Design Environment for Composites (CADEC) ${ }^{22}$ was used to creatively engage students in the design and analysis of composites (see Computer Lab Sessions in Figure 5). To disseminate the teaching guides, a course website as a delivery medium is under development and now available at: http://gozips.uakron.edu/ qiao/compmat/compmat.htm.

\section{Conclusions}

An "active learning" concept presented briefly in this article has been applied to teaching and learning of advanced composite materials in civil engineering curricula and implemented jointly at West Virginia Universities (WVU) and the Univ. of Akron (UA), Ohio for senior undergraduate and beginning graduate students. Based on exit-surveys and feedback of students at WVU and UA, the major benefit to undergraduate civil engineering students has been the effectiveness of the active learning approach for students to grasp relatively complex topics of composite materials by conceptualization through physical experiments and computer simulations. This course was taught twice at WVU and once at the University of Akron-OH. We are in the process of compiling assessment of learning outcomes, based on student evaluations of instruction, performance in quizzes, tests, and projects, and numerous favorable comments and testimonials. We are confident that the concept discussed in this paper significantly facilitates and enhances the learning of students, and we will continue to explore and improve the present innovations. We believe that this methodology based on collaborative environments can promote higher learning and life-long learning skills and increase interest of students.

\section{Acknowledgments}

Financial support for this study was received from the Combined Research Curriculum Development (CRCD) program of the National Science Foundation (EEC-9700772) and West Virginia University. We thank Dr. Ever J. Barbero of WVU for his help with the experimental program. We also thank Professor Siegfried Holzer of Virginia Tech for sharing his innovative

Proceedings of the 2003 American Society for Engineering Education Annual Conference \& Exposition Copyright (c) 2003, American Society for Engineering Education 


\section{FRP Composite Materials in Civil Engineering}

1. INTRODUCTION (Overview of composites and their applications in civil infrastructure)

2. MATERIALS (Constituents: fibers and resins)

3. MANUFACTURING PROCESSES (Concentration on processes suitable for structural applications, such as bag molding, RTM, pultrusion, filament winding, etc.)

4. LABORATORY MANUFACTURING OF COMPOSITE LAMINATED PANELS (Use of vacuum bagging for fabrication of composite plates)

5. MICROMECHANICS (Conceptual understanding of the theory and applications to simple cases)

6. COMPUTER LAB SESSION (Micromechanics analysis)

7. PLY MECHANICS (Conceptual understanding of stress and strain, coordinate transformations, transformed reduced stiffness matrix, and special cases)

8. COMPUTER LAB SESSION (Ply mechanics analysis)

9. LAMINATE MECHANICS (Conceptual understanding of plate stiffness and compliance, coupling effects, computation of stresses, definition of laminate types, engineering elastic constants, and design)

10. COMPUTER LAB SESSION (Laminate analysis)

11. LABORATORY SESSION (Tensile stiffness and strength of coupon samples, shear stiffness and strength of notched samples)

12. FAILURE AND STRENGTH CRITERIA IN DESIGN (Conceptual understanding of relevant failure criteria and applications in design)

13. THIN-WALLED BEAMS (Overview of mechanics of laminated beams, engineering equations for beam stiffnesses, conceptual understanding of global and local buckling, and simplified design equations for FRP thin-walled beams)

14. COMPUTER LAB SESSION (FRP beam analysis)

15. LABORATORY SESSION (Displacements and strains for simply-supported beams, lateral torsional buckling)

16. FIELD TRIP (e.g., visit a pultrusion plant)

17. COLUMN BEHAVIOR (Euler's column buckling, local buckling, compressive strength, mode interaction, and design equations for buckling of FRP column)

18. LABORATORY SESSION (Lateral and local buckling of columns)

19. ADVANCED COMPOSITE BRIDGES: DESIGN AND APPLICATIONS (Case applications, design aspects and considerations, and systematic design of FRP bridges)

20. REINFORCEMENT OF CONCRETE WITH FABRICS (Applications in practice, design equations for concrete beams wrapped with composite fabrics, fracture toughness and design of the interface bond)

21. REINFORCEMENT OF WOOD WITH PLATES OR FABRICS (Applications in practice, qualification test methods for interface bond performance, fracture toughness of the interface, and design of reinforced glulam beams)

22. LABORATORY SESSION (Testing of control and reinforced concrete-FRP and woodFRP beams; comparisons of failure loads, displacements and strains)

Figure 5 Topics covered in ACM for civil engineering students

Proceedings of the 2003 American Society for Engineering Education Annual Conference \& Exposition Copyright (c) 2003, American Society for Engineering Education 


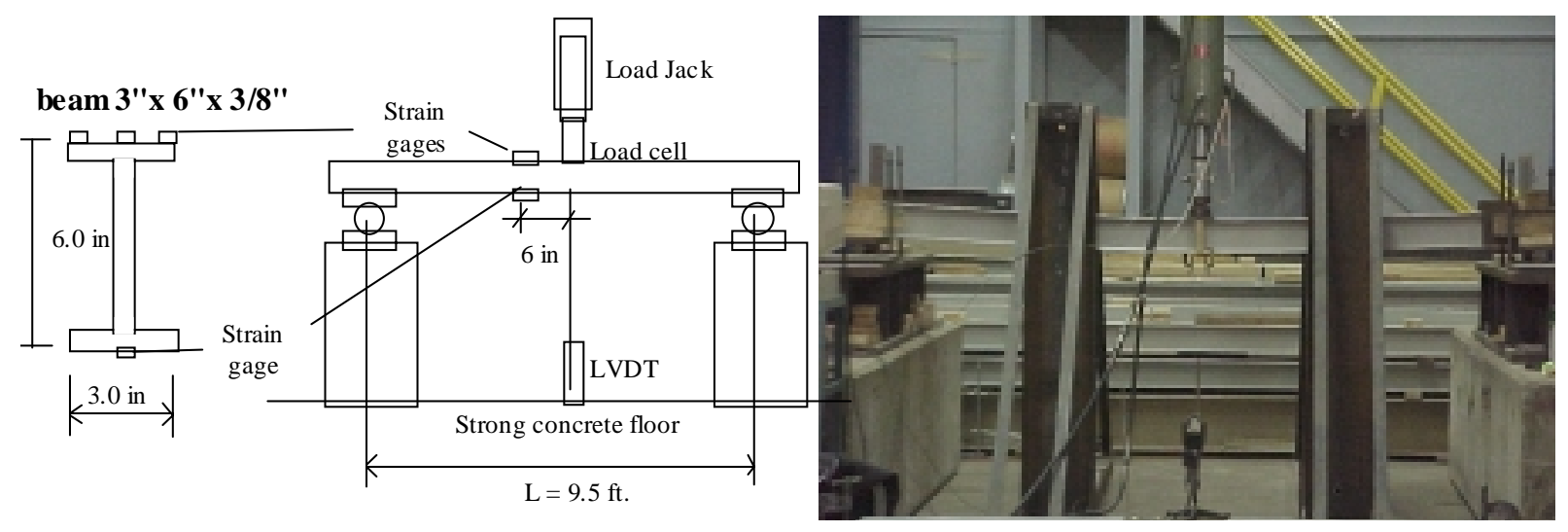

Figure 6 ACM beam under bending.

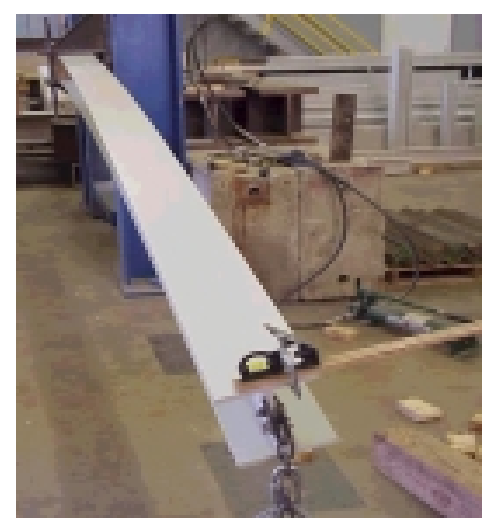

Figure 7 Lateral buckling of ACM beam.

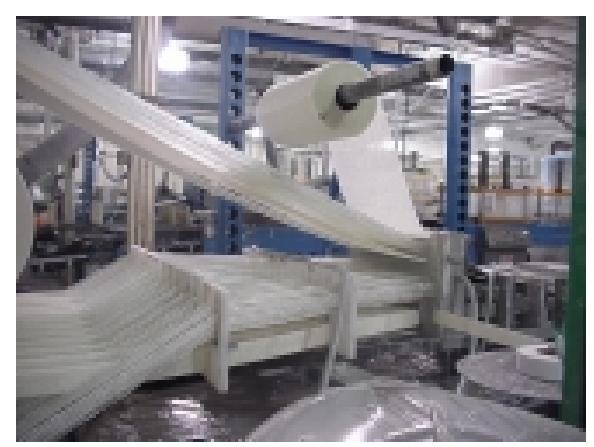

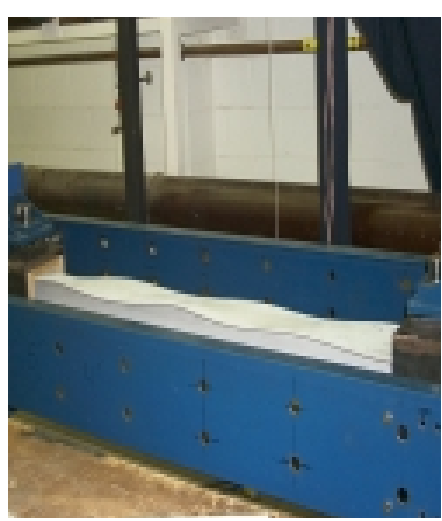
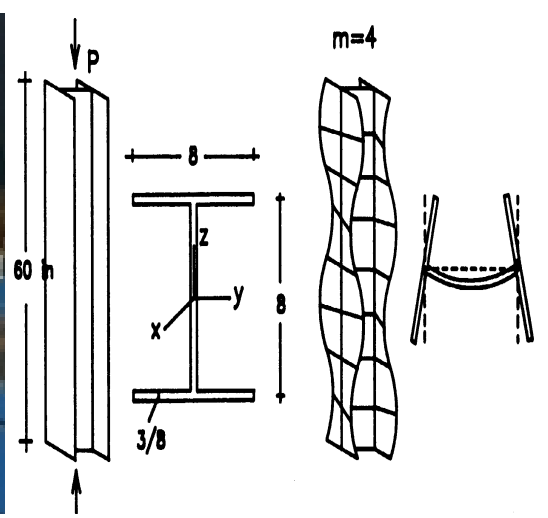

Figure 8 Local buckling of ACM column.

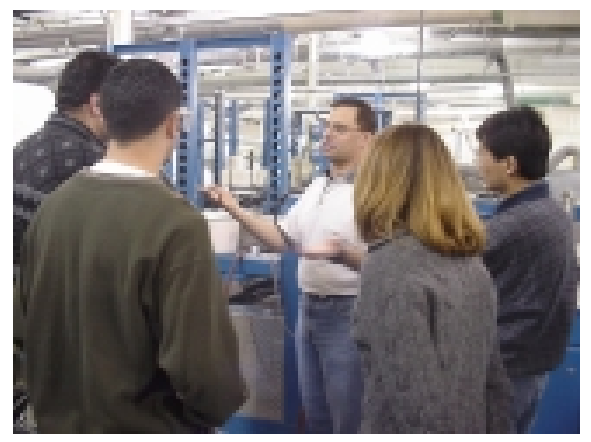

Figure 9 Field trip to a composites manufacturing plant.

Proceedings of the 2003 American Society for Engineering Education Annual Conference \& Exposition Copyright (c) 2003, American Society for Engineering Education 
teaching ideas with us and for inspiring us to pursue teaching excellence. We appreciate the support provided by Dustin Troutman of Creative Pultrusions Inc.

\section{Bibliography}

1. Cross, K.P., "Effective College Teaching," ASEE PRISM, October, 1991, pp. 27-29.

2. Bank, L.C., Davalos, J.F., Mirmiran, A., Mottram, J.T., Neale, K.W. and Ueda, T., "A World Survey of Civil Engineering Programs on FRP Composites for Construction," ASCE J. Professional Issues in Engineering Practice and Education, (In Press), Edited by A.Mirmiran. Feature Article for a Special Issue on Composites Materials Curricula in Civil Engineering for the $150^{\text {th }}$ Anniversary of ASCE, 2002.

3. Bonwell, C.C. and Eison, J.A., Active Learning: Creating Experiment in the Classroom, The George Washington University, School of Education and Human Development, Washington, D.C,1991.

4. Sell, G.R., "Challenges in Using Technology for the Improvement of Undergraduate Education," Teaching Excellence - Toward the Best in the Academy, 8(2). A publication of the Professional and Organizational Development Network in Higher Education, Ed. K.H. Gillespie, Univ. of Georgia, Office of Instructional Development, Athens, GA,1997.

5. Felder, R.M., SUCCEED Teaching Effectiveness Workshop, North Carolina State University, Raleigh, NC, June 10-11, 1994.

6. Holzer, S.M. and Andruet, R.H., "A Multimedia Learning Environment for Statics," Proc. ASCE Structures Congress XII, Atlanta, GA, 1994, Vol. 1, pp. 308 - 314.

7. Holzer, S.M., "From Constructivism to Active Learning," The innovator, The SUCCEED Newsletter, No. 2, Spring 1994, pp. $4-5$.

8. Davalos, J.F. and Moran C.J., "Laboratory Manual for Structural Analysis: An Active Learning Approach," Department of Civil and Environmental Engineering, West Virginia University, 1996, Revised 1998, pp. 210.

9. Piaget, J., The Construction of Reality in the Child, Basic Books, New York, NY, 1954.

10. Kolb, D., Experiential Learning, Prentice Hall, Englewood Cliffs, NJ, 1984.

11. Perelman, L.J., "The End of Education," Washington Post Education Review, November 1,1992.

12. Bakis,C.E,Bank, L.C., Brown, V.L., Cosenza, E., Davalos, J.F., Lesko, J.J., Machinda, A., Rizkalla, S.H. and Triantafillou, T.C., "Fiber-Reinforced Polymer Composites for Construction - State-of-the-Art Review," Journal of Composites for Construction, ASCE, Vol 6,No. 2, 2002. pp. 73-87. (ASCE $150^{\text {th }}$ Anniversary Paper).

13. Davalos, J.F. and Barbero, E.J., "Advanced Composites in Civil Infrastructure," Testimony before the Subcommittee on Science, Technology, and Space; Committee on Commerce, Science, and Transportation. Hearing on The Uses of Advanced Materials in Civil Infrastructure. U.S. Senate, Washington, D.C., May 27, 1993. pp. 35-40, various attachments. U.S. Government Printing Office, Washington D.C. 20402 (ISBN 0-16-043446-7).

14. Seible, S., and Karbhari ,V., "Advanced Composites Built on Success," Civil Engineering, August, 1996, pp. 44-47.

15. Davalos, J. F., Salim, H. A., Qiao, P. Z., Lopez-Anido, R., and Barbero, E. J., “Analysis and design of pultruded FRP shapes under bending", Composites, Part B: Engineering Journal, Vol. 27,No.(3-4),1996, pp. 295-305.

16. Davalos, J. F. and Qiao, P. Z., "A computational approach for analysis and optimal design of FRP beams", Computers and Structures, Vol. 70,No.2,1999,pp. 169-183.

17. Davalos, J. F. and Qiao, P. Z., "Analytical and experimental study of lateral and distortional buckling of FRP wide-flange beams," Journal of Composites for Construction, ASCE, Vol. 1, No. 4, 1997, pp. 150159.

18. Qiao, P. Z. and Davalos, J. F., "Flexural-Torsional Buckling of FRP Composite Cantilever I-Beams",

Proceedings of the 2003 American Society for Engineering Education Annual Conference \& Exposition Copyright (c) 2003, American Society for Engineering Education 
Engineering Structures, In press, 2002.

19. Barbero, E. J. and DeVivo, L., "Beam-Column Design Equations for Wide-Flange Pultruded Structural Shapes", ASCE Journal of Composites in Construction, Vol. 3, No. 4, 1999, pp. 185-191.

20. Barbero, E. J., "Prediction of Buckling-Mode Interaction in Composite Columns", Mechanics of Composite Materials and Structures, Vol. 7, 2000, pp. 269-284.

21. Qiao, P. Z., Davalos, J. F., and Wang, J. L., "Local buckling of composite FRP shapes by discrete plate analysis", Journal of Structural Engineering, ASCE, Vol. 127, No. 3, 2001, pp. 245-255.

22. Barbero, E. J., Introduction to Composite Materials Design, Taylor \& Francis, Philadelphia, PA, 1998.

\begin{abstract}
About the Authors
JULIO F. DAVALOS

Julio F. Davalos is the C.W. Benedum Distinguished Teaching Professor at West Virginia University and Professor of Civil and Environmental Engineering, with B.S., M.S., and Ph.D. in Civil Engineering from Virginia Tech. He received numerous teaching and research awards including four-times Teacher of the Year in the College (1995, '96, 2000, '01), WVU Outstanding Teacher (1995), Professor of the Year in the State of West Virginia (1998). His research expertise includes structural mechanics, advanced materials, and innovative teaching methods and technologies.

PIZHONG QIAO

Pizhong Qiao is Associate Professor of Civil Engineering at the Universality of Akron-OH, with B.S. in Naval Architecture from East China Shipbuilding Institute, M.S. in CE from Florida Atlantic University, and Ph.D. in Structural Mechanics from WVU. He is a registered engineer and his research interests include computational mechanics, characterization of polymer composites and smart materials, and civil structural applications.
\end{abstract}

Proceedings of the 2003 American Society for Engineering Education Annual Conference \& Exposition Copyright (C) 2003, American Society for Engineering Education 